\title{
PENINGKATAN PENGENDALIAN DIRI PADA ANAK TUNA LARAS DENGAN MENGGUNAKAN PENDEKATAN TEKNIK KONSELING BEHAVIORAL DI SMKN 3 BANDUNG
}

\author{
IMPROVEMENT OF SELF CONTROL FOR BEHAVIOR DISORDER CHILDREN \\ USING BEHAVIORAL COOPERATION TECHNIQUE APPROACH AT VOCATIONAL \\ SCHOOL NO. 3 BANDUNG
}

\author{
Aasindriyati \\ SMK Negeri 3 Bandung \\ E-mail: indriyatiaas@gmail.com
}

\begin{abstract}
ABSTRAK
Penelitian ini dimaksudkan untuk memperbaiki perilaku dalam meningkatkan pengendalian diri anak tuna laras melalui modifikasi perilaku. Penelitian ini merupakan penelitian tindakan kelas (action research classroom). Subjek penelitian dalam penelitian ini bernama S siswa tingkat XII jurusan multi media yang berjenis kelamin laki-laki. Teknik pengumpulan data dengan observasi, dokumentasi dan konseling. Instrumen yang digunakan panduan observasi, konseling tertulis, anekdotal record, psikotest. Teknik analisis data, yaitu analisis data kualitatif dan kuantitatif. Indikator keberhasilan $80 \%$ dari total indikator. Hasil penelitian menunjukkan pengendalian diri dapat ditingkatkan melalui modifikasi perilaku. meliputi: (1) pemberian reward, (2) penundaan kesenangan sebagai punishment, (3)memotivasi anak melalui prompt, (4) mengacuhkan anak sebagai tindakan extinction, (5) melakukan tindakan peneladanan, (6) pelatihan pengelolaan diri, (7) pelatihan keterampilan sosial, dan (8) penerapan economic token atau tabungan kepingan.Kemampuan pengendalian diri siswa $\mathrm{S}$ ditunjukkan oleh pencapaian aspek behaviour control, aspek cognitive control, aspek decisional control, dan aspek emotionalcontrol. Pada siklus I skor yang dicapai S adalah 37 atau 11,7 \% (kategori rendah). Pada tindakan Siklus I dilakukan proses konseling tingkat pengendalian emosi.Pada tindakan Siklus II persentasi perubahan perilaku 18, \% atau 5,96\% (kategori sedang). subjek penelitian memiliki tingkat pengendalian emosi cukup baik.
\end{abstract}

Kata kunci:pengendalian diri, teknikkonseling behavioral, anak tuna laras

\section{ABSTRACT}

This research means to improve the behavior to develop self control of emotional handicap childrens. It is class action research. The research subject in this research is S XII grade multi media department, the student is a boy. The observation with technique documentation and instrument counseling. The indicator of result is $80 \%$ of the total indicator. The results showed that self-control can be improved through behavior modification. Including (1) giving rewards, (2) delaying pleasure as punishment, (3) motivating children through prompt, (4) ignoring children as extinction measures, (5) performing modeling actions, (6) self-management training, (7) Social skills training, and (8) implementation of economic tokens or saving pieces. In the first cycle the result of research 11,7 of developing self control of emotional. In second cycle self control of emotional has result 18 (5,96\%) the medium categori.The research subject has fairly good level of emotional self control

Keywords: self-control, behavioral counseling techniques, emotional handicap children

\section{PENDAHULUAN}

Undang undang pendidikan No. 20 tahun 2003 tentang sistem pendidikan nasional penjelasan pasal 15 dan 32 tersirat perlu diselenggarakan pendidikan inklusif bagi peserta didik yang memiliki kelainan atau penyandang disabilitas. Permendiknas no 70 tahun 2009 yang menyebutkan bahwa pendidikan inklusif sebagai sistem penyelenggaraan pendidikan memberi kesempatan bagi peserta didik yang memiliki kelainan atau potensi istimewa untuk mengikuti pendidikan atau Jurnal Penelitian Pendidikan pembelajaran dalam lingkungan pendidikan secara bersama sama dengan peserta didik pada umumnya. Penelitian ini akan berfokus pada anak tuna laras. Kesulitan anak tuna laras dalam berekspresi dapat menumbuhkan rasa prustasi, kendala komunikasi, sikap penolakan, bertindak agresif, kebimbangan dan keraguraguan. Pada umumnya anak tuna laras memiliki inteligensi normal dan rata-rata, akan tetapi karena kendala dalam perkembangan komunikasi sosial akan menampakkan inteligensi yang rendah. 
Salah satu stimulasi yang perlu dilakukan pada anak tuna laras adalah pengendalian diri.

Pengendalian diri akan memandu perilaku agar sesuai dengan norma dan nilai yang berlaku untuk mencapai kebahagiaan.

Hasil penelitian pada anak tunarungu di kelas C TKLB SLB Negeri 2 Bantul Kemampuan pengendalian diri siswa $\mathrm{S}$ ditunjukkan oleh pencapaian aspek behaviour control, aspek cognitive control, aspek decisional control, dan aspek emotionalcontrol. Pada siklus I skor yang dicapai adalah 24 atau 57,715\% (kategori sedang). Pada tindakan Siklus II persentasi perubahan perilaku 31 73,31\% (kategori sedang). subjek penelitian memiliki tingkat pengendalian emosi yang tinggi.

Pada tindakan Siklus III pengendalian emosi persentasi perubahan perilaku adalah 38 (90,44\%) termasuk kategori tinggi.

Dengan berlandaskan pada teori belajar operan, fikasi perilaku menegaskan bahwa perilaku cenderung diulang jika dikuatkan oleh ganjaran positif, yang dapat berupa hadiah atau sesuatu yang menyenangkan. Sebaliknya sebuah perilaku cenderung tidak diulang/berhenti jika disertai dengan pemberian sebuah hukuman. Hal tersebut akan membantu dan merangsang anak untuk selalu berbuat sesuai dengan aturan atau bentuk perilaku yang diharapkan, sehingga perkembangan kepribadian anak tuna laras dapat selaras dengan perkembangan kepribadian secara wajar

Modifikasi perilaku yang dilakukan pada anak tuna laras mengarah pada teknik mengubah perilaku dengan teknik konseling behavioral, seperti mengubah perilaku dan reaksi seseorang terhadap suatu stimulus melalui penguatan perilaku adaptif dan/atau penghilangan perilaku maladaptif melalui hukuman.

Penelitian ini untuk mengetahui minat belajar, kemampuan pengendalian diri, Kemampuan bahasa reseptif dan ekspresif, kemampuan dalam bertanggungjawab dan meningkatkan fokus perhatian pada pelajaran di kelas sehingga guru mendapatkan gambaran tentang upaya perlakuan, dan peningkatan pengendalian diri sebagai salah satu alternatif stimulasi yang dilakukan pada siswa, khususnya pada anak berkebutuhan khusus dengan ketunaan yang sejenis.

William M. Cruickshank dalam Anamirah (2012: 16-19) mengemukakan bahwa anak yang mengalami hambatan sosial dapat diklasifikasikan ke dalam kategori berikut.

a. The semi-socialize child

Anak yang dapat berhubungan sosial tetapi terbatas pada keluarga atau kelompoknya.

b. Children arrested at a primitive level or socialization

Anak yang perkembangan sosialnya berhenti pada level yang rendah dan kurangsikap sosial serta terlantar dari pendidikan

c. Children with minimum socialization capacity

Anak yang tidak memilikikemampuan untuk belajar sikap sosial.

Anak yang mengalami gangguan emosi diklasifikasikan sebagai berikut:

a. Neurotic behavior (perilaku neurotik) Anak dapat berhubungan sosial tetapitidak mampu menyelesaikan masalah sendiri.

b. Children with psychotic processes Anak yang memerlukan penanganan khusus.

Hallahan dan Kauffman (1986) dalam Suwardani (2012) mengklasifikasikan tuna laras berdasarkan dimensi tingkah laku sebagai berikut:

a. Anak yang mengalami gangguan perilaku.

b. Anak yang mengalami kecemasan dan menyendiri.

c. Anak yang kurang dewasa.

d. Anak yang agresif bersosialisasi

e. Karakteristik akademik, hasil belajar di bawah rata-rata, tidak naik kelas, sering membolos, sering melakukan

Jurnal Penelitian Pendidikan 
pelanggaran, baik disekolah maupun di masyarakat.

f. Karakteristik hambatan Sosial/ Emosional/Fisik

Menurut Berk dalam Gunarsa (2004:251) pengendalian diri adalah kemampuan individu untuk menahan keinginan atau dorongan sesaat yang bertentangan dengan norma sosial. Pengendalian diri berkaitan erat dengan kemampuan mengelola emosi diri dalam menjalin hubungan dengan orang lain.

Menurut Averill dalam Purwanti (2014, 28-31) pengendalian diri memiliki 3 aspek dalam kemampuan pengendalian diri, yaitu behaviour control, cognitive control, dan decisional control. Kemudian Hurlock dalam Purwanti (2014, 28-31) juga menambahkan satu aspek lagi dalam pengendalian diri yaitu emotional control.

Menurut Sugiharto dalam Sudrajat (2008) konseling behavioral dapat dipakai untuk melatih anak yang mengalami kesulitan untuk menyatakan diri yang mengalami kesulitan untuk menyatakan diri melalui latihan Asertif, melakukan teknik Desensitisasi Sistematis untuk menenangkan anak dari ketegangan,

Teknik ini dapat digunakan untuk menghilangkan kebiasaan buruk dengan mengkondisikan Aversi, dan membentuk tingkah laku baru pada anak, dan memperkuat tingkah laku yang sudahterbentuk (model).

\section{METODA PENELITIAN}

Desain penelitian ini bersifat deskriptif kualitatif dengan menggunakan rancangan Kemmis dan Taggart meliputi perencanaan, tindakan, pengamatan, melakukan refleksi dan merancang tindakan selanjutnya (Suharsimi Arikunto, 2010: 132). seperti pada gambar berikut:

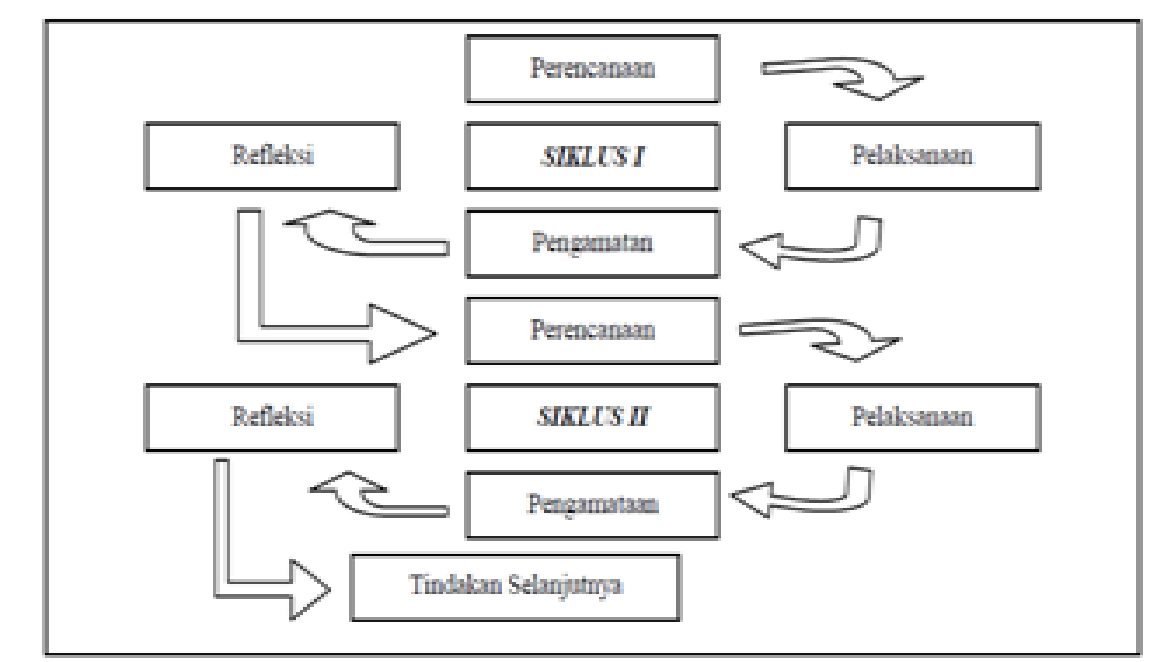

\section{HASIL PENELITIAN DAN PEMBAHASAN}

Subjek dalam penelitian ini Perkembangan bahasa represif cukup baik tetapi bahasa ekspresifnya masih rendah. S apabila berkomunikasi tidak jelas, sering kehilangan dan belum bisa mengubah perilaku maladaptif kondisi tersebut diperlukan latihan perilaku, seperti semangat dalam belajar, berbagi masalah, membantu teman, mengikuti instruksi guru dengan patuh, dan mengerjakan tugas dengan baik. Hal ini perlu dilakukan, agar perkembangan perilaku dapat diarahkan ke perilaku yang positif.

Hasil analisa anecdotal record, S sering menyendiri atau merasa malu jika ada teman yang baru dikenalnya terutama jika lawan jenis, merasa tidak nyaman dengan situasi lingkungan baru, sering kehilangan fokus saat belajar menyelesaikan tugas dari guru tetapi tidak pernah tuntas, membanting hp yang dibawanya memukul laptop saat menemui kendala waktu menyelesaikan tugas, motivasi belajarnya rendah, dan hanya menyukai pelajaran yang dia minati saja.

Hasil observasi menunjukkan bahwa 
aspek behaviour control mendapat skor 16 $(2,3 \%)$ katagori rendah, aspek cognitive mendapat skor $6(2,5 \%)$ katagori rendah, aspek decisional control mendapat skor 6 $(3,0 \%)$ katagori rendah dan aspek emotional control mendapat skor $9(3,6 \%)$ katagori rendah. Dari hasil siklus I totalitas nilai untuk kemampuan siswa dalam pengendalian diri $(11,4 \%)$ katagori rendah.

Hasil konseling dengan teknik behavioral ditekankan pada penuntasan tugas selesai tepat waktu, menguatkan rasa percaya diri, kemampun mengendalikan emosi dan cara efektif untuk mengubahnya menjadi energi yang positif kemampuan siswa dalam memanajemen rasa cemas, menggali perasaan, mengeksplorasi hal hal yang menjadikan rasa minder, mengulas gangguan fisik, mensiasati tugas-tugas pembelajaran, dan memberi latihan dan penguatan kepada siswa untuk mengendalikan emosi.

Pada langkah ini dilakukan analisa terhadap hasil konseling mencakup analisa ekspresi wajah klien, mengeksplorasi perasaan klien dan mengecek pola klien dalam usahanya mengendalikan emosi, menanggapi respon positif terhadap reward yang diterima dari jurusan dan menguatkan pola pengendalian emosi di masa yang akan datang.

1) Kemampuan $\mathrm{S}$ untuk berkomunikasi dengan teman lebih meningkat dan tingkat kecemasan sudah menurun tetapi komunikasi dengan lawan jenis masih membutuhkan penguatan.

2) Gangguan fisik seperti pusing, perut sakit, air liur berlebihan bisa direpresi bila merasa nyaman dengan lawan berbincang, atau tugas dalam pembelajaran dapat diselesikan dengan baik.

3) Kemampuan siswa $\mathrm{S}$ dalam mengantisipasi kemarahan sudah sangat baik dengan cara diam menahan diri lalu berusaha menuliskan apa yang dia inginkan atau rasakan dalam bentuk tulisan, kebiasaan membanting hp atau memukul komputer sudah tidak dilakukan. Apabila emosi muncul dikendalikan dengan diam lalu menyampaikan saat emosi sudah mereda jika ingin marah memukul benda dialihkan dengan mengubah objek bendanya menjadi benda yang tidak berbahaya seperti penghapus karet, topi atau jaket.

4) Siswa diberi latihan berani memulai hubungan sosial dengan lawan jenis, mengemukakan pendapat secara terbuka

\section{SIMPULAN}

1) Belum semua perubahan yang positip dapat dihasilkan dari seluruh konseling perlu dilatihkan mengatasi minder di lingkungan dengan orang baru, sedih tanpa tahu sebab, sulit mengendalikan gangguan symtom fisik, tidak dapat dengan mudah menemukan pola pengendalian emosi untuk menanggapi situasi dan kondisi yang lebih komplek

2) Siswa menunjukkan rasa senang, malu, bahagia secara ekspresif

3) Pemberian reward bagi siswa agar percaya diri, merasa lebih berarti, penghargaan diri dan menjadi dorongan kuat untuk berprestasi

4) Konseling behavioral untuk masalah seperti $S$ sangat efektif dalam mengubah perilaku dan pengendalian emosi

Kemampuan mengendalikan diri siswa yang meningkat mampu membuat penyesuaian diri dengan lingkungan sekitarnya.

1. Rendahnya minat belajar pada anak tuna laras disebabkan karena faktor kesulitan dalam menyampaikan pemikiran dengan bahasa reseptif.

2. Rendahnya kemampuan pengendalian diri pada anak tuna laras karena anak tidak menemukan cara efektip untuk mengelola reaksi kemarahan yang agresif jadi menguntungkan bagi 
pengembangan dirinya sehingga perlu dilatihkan cara cara efektif dalam mengendalikan diri dari rasa marah, kesal dan tidak berdaya.

3. Kemampuan bahasa reseptif dan ekspresif pada anak tuna laras masih rendah, kemampuan ini dapat dikembangkan apabila anak memiliki kepercayaan diri yang tinggi, berani tampil berbeda, penerimaan diri yang baik, tidak merasa minder dengan orang lain dan lingkungan pergaulan yang menerima dirinya dengan terbuka.

4. Kemampuan dalam bertanggungjawab anak tuna laras dalam menyelesaikan tugas mata pelajaran masih rendah, diperlukan bantuan dari guru pengajar dan komunikasi dengan orang tua agar tugas tugas anak tuntas di sekolah maupun di rumah, kolaborasi ini penting karena anak mudah teralihkan fokus saat mengalami kesulitan dalam menuntaskan tugas belajarnya.

5. Rendahnya pemusatan perhatian pada anak tuna laras pada pelajaran di kelas. Hal ini karena anak tuna laras cenderung menyukai bidang pekerjaan yang diminatinya saja sehingga perlakuan dalam pembelajaran tidak dapat disamakan seperti perlakuan pada anak yang lainnya.

\section{Rekomendasi}

1. Diperlukan pemahaman guru pengajar di kelas bahwa anak tuna laras dapat memahami bahasa reseptif di kelas tetapi mengalami kesulitan untuk mengungkapkan dengan bahasa reaktip sehingga diperlukan usaha guru agar anak nyaman dan mau melakukan tugas tugas seperti yang diminta dalam belajar.

2. Diperlukan kemampuan guru mengelola kemarahan saat anak tuna laras tidak mampu mengendalikan emosi, rasa kecewa dan kesal dengan ketidakberhasilannya melalukan suatu tugas.

3. Memberikan bentuk penghargaan atau reward saat anak sukses melakukan suatu kompetensi, apresiasi lingkungan sekitar membuat anak lebih percaya diri, tidak minder dan merasa berguna.

4. Keterlibatan guru secara pribadi kepada anak tuna laras dapat menimbulkan motivasi belajar, dan menumbuhkan ketertarikan kepada materi yang diajarkan, sebaliknya guru yang kurang memperhatikan siswa ini akan melihat penolakan dan memandang siswa ini menjadi gangguan, hambatan ini cukup menghalangi anak dengan tuna laras untuk tumbuh kembang.

\section{DAFTAR RUJUKAN}

Anamirah.(2012). Penanganan Emosi Melalui Permainan Sepak Bola pada Anak Tuna laras Tipe Hiperaktif Kelas I SDLB di SDLB-E Prayuwana Yogyakarta. Skripsi : FIP UNY Yogyakarta

Gunarsa, Singgih. D. (2004). Seri Psikologi Bunga Rampai Psikologi Perkembangandari Anak sampai Usia Lanjut. Jakarta : PT. BPK Mulia.

Peraturan Pemerintah Nomor 72 tahun 1991 tentang Pendidikan Luar Biasa.

Purwanti, Tri.(2014).Peningkatan Pengendalian Diri Melalui Modifikasi Perilaku pada Anak Tunarungu di Kelas $C$ TKLBSLB Negeri 2 Bantul. Skripsi: FIP UNY Yogjakarta.

Suharsimi Arikunto.(2010). Penelitian Tindakan Kelas. Jakarta: Bumi Aksara.

Tim Pengembang Ilmu Pendidikan FIP UPI.(2007).udanAplikasiPendidikanBagian 2 IlmuPendidikanPraktis. Bandung: PT. Imperial Bhakti Utama 